\title{
Design and Implementation of an E-commerce Platform for Textile Destocking Problem
}

\author{
Zhihua Feng ${ }^{1, a^{*}}$, Sen $\mathrm{Gao}^{2, \mathrm{~b}}$, Zhiqiang Tan $^{3}$, Jianke Zheng ${ }^{3}$, Xin Luo ${ }^{1}$ \\ ${ }^{1}$ School of Computer Science \& Technology Donghua University, Shanghai 201620, China; \\ ${ }^{2}$ Hebei Sanluwu Network Technology Group Co., Ltd, Hebei 050061, China; \\ ${ }^{3}$ Dongguan Humen clothing innovation service center, Dongguan 523000, China; \\ afengzhihua2012cc@163.com, ${ }^{b}$ gaosencd@163.com
}

Keywords: Textile; E-commerce Platform; Destocking; PHP; Web

\begin{abstract}
With the popularity of the Internet and e-commerce, new business models bring consumers more information and choices. The problem of excessive inventory for textile fabric company has intensified. Traditional company destocking methods are single and inefficient, and they must combine e-commerce platforms to effectively destocking. For this issue, this paper designed to implement a convenient and efficient Textile fabric e-commerce platform, including product information, order management, membership management, payment, distribution, advertising and other functions, on the basis of php + MySQL website technology. The MySQL database is designed by efficient fabric classification method, adopting B/S architecture and MVC development mode to realize simple and efficient fabric e-commerce platform.
\end{abstract}

\section{Introduction}

Destocking [1] is a major challenge and opportunity for the development of textile fabric companies today. Under normal circumstances, the main means for companies to destocking is the concentration of their own physical inventory market and 'Unprofitable trading'. As the overall industry's profitability continues to decline, inventory has become a "profit point" for textile fabric companies. How to effectively reduce inventories and turn discarded inventories into valuable ones has become a top priority in the development of modern textile fabric enterprises.

The traditional e-commerce platforms [2] are mostly "third-party sellers" and cannot guarantee the requirements for efficient destocking of fabrics, nor can they guarantee the high quality and authority of fabrics. Therefore, it is very necessary to design and develop an e-commerce platform that is "self-operated", "equitable and transparent" for the textile fabric market segment.

\section{System Requirements and Functional Analysis}

This system is a sales management system for the textile fabrics inventory market. In the production and sales process of textile fabric companies, there will be surplus of inventory fabrics during production, season change, clearance, conversion, debt repayment, and auction. In the past, most of the methods used by textile fabric companies to deal with inventory were low-priced dumping at market stores and low-cost packaging for the storage and sale of stock fabrics companies, regardless of the manner in which the company's interests were compromised. The e-commerce platform for stocking fabrics has made the seemingly obsolete inventory fabrics a commodity again, which has achieved the best results and increased the benefits of the company. Therefore, designing such an e-commerce system [3] is imperative.

After careful research and analysis of the business processes and industry characteristics of textile fabric sales, we have determined the basic functions and special needs of the entire platform. The textile fabric e-commerce platform needs to satisfy the customer's one-stop shopping process [4], including browsing products, registering for registration, submitting orders, and order management. Among them, because the goods are textile fabrics, the platform needs to provide customers with a clear display of fabrics, including the fine classification of fabrics, detailed 
information on fabrics, and making the user's selection process as smooth as possible. The backstage section mainly includes the platform administrator management platform members, who have performed, checked, deleted, and changed the platform members.

\section{System Design}

Functional module design. According to the requirements of the textile fabric e-commerce platform, the platform design can be simply divided into two parts: the front desk and the back office. The front desk part mainly includes the login registration module, the mall module, and the order management module [4]. The backstage includes a system setting module and a member management module. Each module has its own independent function and completes the functions of a sales system. The front page is written by HTML, CSS, JS, etc. The background page is written by PHP [5], HTML, CSS, JS, etc. The functional modules of the fabric e-commerce platform are shown in Figure 1.

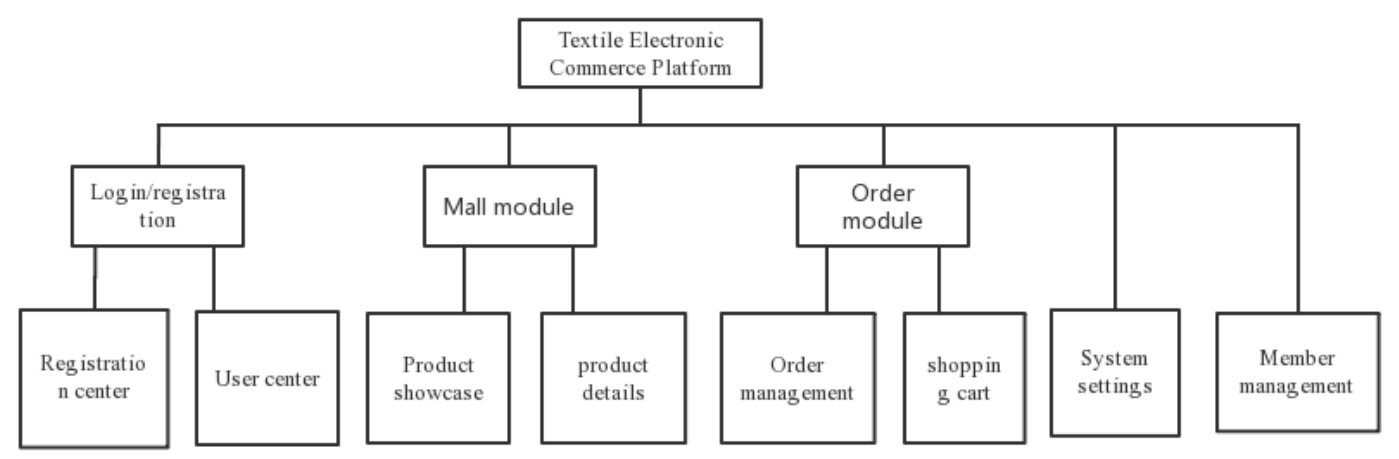

Figure 1. Fabric e-commerce platform module diagram

(1) Login registration module: Including the registration center before login and the user center after login. The registration center provides different types of user registration. After the user logs in, he or she can modify the personal information and order information in the user center.

(2) Shopping Mall Modular: Include a list of all products and a detailed content page of the product. The list is displayed according to the system classification. The detail page contains the detailed picture display of fabrics and other related data, and an evaluation page is also integrated on the details page.

(3) Order management module: After the user selects a product, it can be added to the shopping cart, click submit to generate an order. The user can modify the order or return before the merchant confirms.

(4) System settings: The system administrator logs in to the background to manage the entire platform, including the basic settings of the platform, management of merchandise on the shelves, order management, and real-time updating and maintenance of the platform.

(5) Membership management: After the system administrator logs in the background, he can manage the members, including the rights management of the members and the addition, deletion, and change.

Database Design. The data storage and application of this system is designed based on MySQL [6] database. Since the stored information is mainly fabric, in order to achieve an efficient fabric retrieval effect, detailed and concise classification of the fabric must be performed. This paper uses its own set of fabric coding methods to encode fabrics. We divided the fabric samples into 10 categories based on the raw materials and the manufacturing process. We use the numbers ' 1 '- ' 10 ' to represent them and ' 0 ' represents ' 10 '. Each major category is divided into a number of subcategories, represented by numbers ' 1 ' -6 '. The following gives some of the classification instructions, the specific classification can be seen in Table 1. 
Table 1 Fabric classification diagram

\begin{tabular}{|l|l|}
\hline Large class & Small class \\
\hline 1 Chemical fiber & $\begin{array}{l}1-1 \text { Polyester 1-2 Nylon 1-3 Acrylic 1-4 Polypropylene 1-5 } \\
\text { other }\end{array}$ \\
\hline 2 Cotton & $\begin{array}{l}2-1 \text { plain weave 2-2 twill 2-3 yarn weave 2-4 double layer } \\
\text { (multi-layer) 2-5 herringbone oblique }\end{array}$ \\
\hline
\end{tabular}

The user table mainly stores brief personal information such as the user's name, telephone number, and address, etc. The merchant table mainly provides brief company information such as the name of the stock merchant, the main fabric type, telephone, and address; the fabric information sheet mainly provides the attributes of the fabric, such as product name, composition, weight, color fastness and other details. The order form mainly provides detailed information such as order number, order time, order status, order contents and so on.

\section{System implementation}

Platform implementation. The experimental process of this platform is summarized as follows: In this system, the background obtains the parameters through the URL [7] and then calls the corresponding module file, then parses the file through the template engine to get the executable PHP file, and then the server processes the php file. The web server calls the data in the database while processing the php file, and then returns to the web page. This system caches the static home page and fabric details page, and no longer calls the corresponding html file in the view template repeatedly. The implementation of the database link is mainly implemented in the DB_MySql class to provide effective data for the platform.

Platform function module implementation.

Login registration module: registration is to submit a form from the front-end web page to the background, and then through the php function to insert into the mysql database to complete the registration. Registration involves the selection of user types. The registration function also provides a mechanism for determining the identity of registered users. The login is to compare the form passed in the front end with the corresponding registry in the database, and to display the corresponding user interface after judging the user's identity.

Mall module: It mainly displays the fabric list. The fabric list is displayed in the form of a simplified schematic of the fabric, and then classified according to the classification of this article, the user can easily find the type of fabric he wants. Shopping cart and order management pages are also integrated in the mall module. The fabric details page links to the thumbnails, which also contains a fabric 'star rating' pages that is integrated with jQuery. The 'star rating' is based on the fabric provided by the fabric manufacturer, we evaluate it expertly. The evaluation content is six quantifiable evaluation attributes: price, density, color fastness, thickness, wear resistance, and comfort. Reflects this platform is a " equitable ", "transparent" self-owned fabric sales platform.

Administrator management module: The administrator manages the permissions that the user has. This system uses php to write background management page. Writing a different function owned by different roles in a function and store it in an array. Then write a file to judge the user's permission according to the ID of the login user, and then refer the above function to a page to implement the administrator. Authority management for system users.

Database implementation. The database [8] is designed to achieve the main data items required by the fabric de-stocking e-commerce platform through MySQL design: user information table, fabric information table, business information table and order table four module information table, part of the data table, such as Table 2, Table 3 show. 
Table 2 User information table

\begin{tabular}{|c|c|c|c|c|c|}
\hline Field & Type & Attribute & Field & Type & Attribute \\
\hline userid & bigint(20) & utf8_general_ci & mobile & varchar(50) & utf8_general_ci \\
\hline username & varchar(30) & utf8_general_ci & qq & varchar(20) & utf8_general_ci \\
\hline password & varchar(32) & utf8_general_ci & address & varchar(50) & utf8_general_ci \\
\hline truename & varchar(20) & utf8_general_ci & & & \\
\hline
\end{tabular}

Table 3 Fabric table

\begin{tabular}{|c|c|c|c|c|c|}
\hline Field & Type & Attribute & Field & Type & Attribute \\
\hline userid & bigint(20) & utf8_general_ci & type & varchar(20) & utf8_general_ci \\
\hline username & varchar(30) & utf8_general_ci & size & varchar(50) & utf8_general_ci \\
\hline company & varchar(32) & utf8_general_ci & address & varchar(50) & utf8_general_ci \\
\hline
\end{tabular}

\section{Summary}

This paper presents a textile fabrics e-commerce platform based on php + mysql technology and implements the mall module on the web page, aiming at the problem of excess inventory of fabrics. This system has changed the sales pattern of traditional third-party sellers of fabrics e-commerce, and developed an e-commerce platform that is "self-operated", "equitable and transparent" for the textile fabric market segment. Of course, there are some limitations in the development and implementation of this system. However, with the continuous development of the society and the continuous improvement of the e-commerce platform, new ideas are provided for the next step.

\section{Acknowledgement}

Dongguan City professional town innovation service platform construction project"Dongguan City Humen garment Collaborative Innovation Center";

Guangdong Province, collaborative innovation and platform for the construction of special funds(Item Number:2014B090908004);

\section{References}

[1] Jiaoyue:"The high inventory crisis in the textile and garment industry is difficult to eliminate 14 textile enterprises inventories exceeding 1 billion yuan'[N]. Securities Daily, 2013-11-01 (C01)(in chinese).

[2] Wu Jianhua: "Problems and Countermeasures in the Development of Textile E - commerce in China"[J]. Industrial Technology Economy,Vol.24(2005) ,No.6, p.109-111(in chinese)

[3] Zhu Pin, Cheng Zhiping:" Website construction based on PHP technology"[J]. Gansu metallurgy, Vol. 30(2008),No.2,p.66-68(in chinese)

[4] Zhan Yuxuan:" E-commerce system design“[M]. Southeast University Press.2002

[5] Quan zhi, Song Jingjing:" Research and Implementation of Dynamic Website Based on PHP'[J]. Computer and network,Vol. 41(2015),No.11,p.52-55(in chinese)

[6] Hu Feng:" Industry Website Based on PHP and MySQL"[J]. Computer Knowledge and Technology,Vol. 12(2016),No.3,p.9-11(in chinese)

[7] Li Qiang:"Based on PHP+MySQL web development research"[J]. Network Security Technology and Application,Vol. 5(2014),p.22-23(in chinese)

[8] Chen Yunfang, Pan Lihua,Chen Rui, et al:“ Implementation of MySQL Database Based on PHP Language"[J]. China New Telecommunications,Vol.17(2015), No.19 ,p.103-103(in chinese) 